\title{
EFFECTS OF POTASSIUM DICHROMATE ON THE SURVIVAL AND REPRODUCTION OF Moina micrura Kurz. 1875 (Cladocera: Moinidae)
}

\section{Trinh Dang Mau*, Le Vu Khanh Trang, Nguyen Nhung Thuy Trinh, Tran Ngoc Son, Vo Van Minh}

Faculty of Biology and Environment Science, The University of Education, Danang University, Danang, Vietnam

Received 19 May 2018, accepted 10 March 2019

\begin{abstract}
Nowadays, heavy metal pollution is an urgent problem in the world including Vietnam. An analytical approach is very important to identify, assess and forecast environmental risks from toxic components, in which ecotoxicology is considered to be the optimal tool. We conducted a study on $M$. micrura in order to contribute the creation of a biological basis for the use of zooplankton as an early warning of the risk of water pollution. The results showed that $M$. micrura was isolated from 29/3 Park Lake, Da Nang City, central Vietnam. The acute toxicity test of potassium dichromate on M. micrura showed LC 50 at 12, 24 and 48 hours were 0.26,

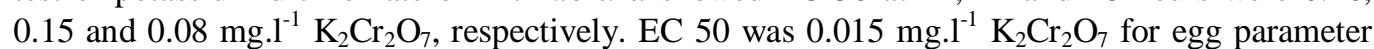
and $0.009 \mathrm{mg} . \mathrm{l}^{-1} \mathrm{~K}_{2} \mathrm{Cr}_{2} \mathrm{O}_{7}$ for neonate parameter. The results of acute and chronic toxicity tests showed that M. micrura was more sensitive than D. magna, D. pulex and C. cornuta.
\end{abstract}

Keywords: Moina micrura, Cladoceran, heavy metals, ecological toxicology.

Citation: Trinh Dang Mau, Le Vu Khanh Trang, Nguyen Nhung Thuy Trinh, Tran Ngoc Son, Vo Van Minh, 2019. Effects of potassium dichromate on the survival and reproduction of Moina micrura Kurz. 1875 (Cladocera: Moinidae), 41(1): 101-107. https://doi.org/10.15625/0866-7160/v41n1.12568.

*Corresponding author email: trinhdangmau@gmail.com

@2019 Vietnam Academy of Science and Technology (VAST) 


\title{
NGHIÊN CÚU ẢNH HƯỞNG CỦA POTASSIUM DICHROMATE ĐẾN Moina micrura Kurz. 1875 (Cladocera: Moinidae)
}

\author{
Trịnh Đăng Mậu* , Lê Vũ Khánh Trang, Nguyễn Nhung Thuỳ Trinh, \\ Trần Ngọc Sơn, Võ Văn Minh \\ Khoa Sinh - Môi trường, Trường Đại học Sư phạm, Đại học Đà Nẵng
}

Ngày nhận bài 19-5-2018, ngày chấp nhận 10-3-2019

\section{TÓM TẮT}

Hiện nay, ô nhiễm kim loại nặng đang là vấn đề rất có tính chất toàn cầu. Cần có phương pháp phân tích để xác định, đánh giá và dự báo các rủi ro môi trường từ các thành phần chất độc, trong đó phương pháp độc học sinh thái được xem là công cụ tối ưu. Chúng tôi đã thực hiện nghiên cứu độc học trên $M$. micrura nhằm góp phần tạo cơ sở sinh học trong việc sử dụng động vật phù du làm sinh vật cảnh báo sớm nguy cơ ô nhiễm nguồn nước. Kết quả đã phân lập được loài $M$. micrura từ hồ Công viên 29/3, thành phố Đà Nẵng. Thử nghiệm độc học cấp tính của potassium dichromate đến loài $M$. micrura cho thấy $\mathrm{LC}_{50}$ tại 3 mốc thời gian 12 giờ, 24 giờ và 48 giờ lần lượt là $0,26 \mathrm{mg} / \mathrm{l}, 0,15 \mathrm{mg} / \mathrm{l}$ và $0,08 \mathrm{mg} / \mathrm{l}$. Đối với thí nghiệm độc mãn tính, kết quả $\mathrm{EC}_{50}$ của $\mathrm{K}_{2} \mathrm{Cr}_{2} \mathrm{O}_{7}$ ảnh hưởng lên số lượng trứng của một con mẹ là $0,015 \mathrm{mg} / \mathrm{L}$ và số lượng con sống là $0,009 \mathrm{mg} / \mathrm{l}$.

Từ khoá: Moina micrura, kim loại năng, độc học sinh thái.

*Địa chỉ liên hệ email: hthue@igr.ac.vn

\section{MỞ ĐẦU}

Cùng với sự phát triển nhanh các khu công nghiệp là sự gia tăng khối lượng các chất ô nhiễm, trong đó kim loại nặng được xem là một trong những mối đe dọa đối với hệ sinh thái và đặc biệt là sức khỏe con người (Kühn, 1989). Hệ thống xử lý nước thải tại nhiều nhà máy, xí nghiệp sản xuất ở Việt Nam vẫn chưa được đầu tư đúng mức, do đó, nước thải chưa đạt tiêu chuẩn xả thải theo yêu cầu, nghiêm trọng nhất là nước thải chứa kim loại nặng. Một trong các kim loại nặng có mức độ nguy hiểm cao đối với sức khỏe con người là hợp chất của chromium. Đây là hợp chất mà Cơ quan Bảo vệ Môi trường Hoa Kỳ đã xác định là một trong những nguyên nhân gây ung thư ở người (Jacobs et al., 2005).

Giám sát nồng độ hóa chất là phương pháp phổ biến được áp dụng rộng rãi để giám sát các chất hóa học trong môi trường. Tuy nhiên nó lại tồn tại một số hạn chế như: không thể phát hiện sự những biến cố thất thường trong môi trường; khoảng thời gian giữa các lần thu mẫu khá dài và không thu được kết quả phân tích tức thời nên nếu có biến cố xảy ra sẽ không thể đưa ra các biện pháp ngăn chặn kịp thời. Để nâng cao hiệu quả chương trình giám sát, việc kêt hợp với các loài sinh vật được áp dụng để bổ trợ cho các phương pháp phân tích lí-hóa. Với mục tiêu này, những nghiên cứu về độc học đã được thực hiện trên nhiều loài sinh vật khác nhau.

Trong số nhiều sinh vật có thể sử dụng để thử nghiệm độc tính môi trường nước, giáp xác râu ngành (Cladocera) được xem là nhóm sinh vật tiềm năng làm chỉ thị cho đánh giá chất lượng nước. Cladocera được sử dụng để phát hiện những thay đổi bất lợi trong môi trường nước thông qua các phản ứng của chúng về hành vi, sinh trưởng, sinh sản và khả 
năng sống sót. Đầu thế kỉ XX, Ernest Warren đã nhận định giống Daphnia, đặc biệt là loài D. magna Straus là một loài điển hình cho nghiên cứu tính độc của sodium chloride, đặt nền móng cho độc học sinh thái (Warren, 1990). Nhiều nghiên cứu sau đó đã tiến hành thử nghiệm ảnh hưởng của các loại độc chất khác nhau lên các loài thuộc giống Daphnia, góp phần tạo cơ sở dữ liệu về ảnh hưởng của độc chất lên loài động vật giáp xác này. Một số kim loại nặng đã được sử dụng để thử nghiệm đánh giá tính độc lên loài này như kẽm, đồng, cadimi, chì (Bodar et al., 1989). Ngoài $D$. magna được sử dụng rộng rãi trong đánh giá độc học, một số loài khác thuộc bộ này cũng đã được thử nghiệm như Ceriodaphnia dubia, Pseudosida ramosa, $C$. cornuta, M. micrura.

Moina micrura, một loài phù du, có phân bố rộng ở nhiều thủy vực nước ngọt nội địa khác nhau. Loài này đã được ghi nhận phân bố rộng trên thế giới, ngoại trừ vùng lạnh (Goulden, 1968). M. micrura là một trong những loài đại diện của nhóm giáp xác Cladocera nhỏ sống ở các hồ nông, hồ ôn đới, ao cá nước lợ nhiệt đới (Petruseket al., 2004). Chúng còn được xem là một trong những sinh vật làm thức ăn tốt cho cá và tôm trong giai đoạn ấu trùng. Trong nghiên cứu của Iwaiet al. (2010), đã chứng minh $M$. micrura có thể sử dụng như sinh vật chỉ thị quan trắc sinh học để đánh giá sự ô nhiễm thuốc trừ sâu trong hệ sinh thái thủy vực Thái Lan.

Ở Việt Nam, nghiên cứu độc học trên các loài Cladocera còn tương đối hạn chế, chưa có sự đa dạng về loài cũng như số lượng độc chất, D.magna là loài được nghiên cứu nhiểu nhất (Lê Huy Tuấn và nnk., 2016; Nguyễn Trung Kiên và nnk., 2017; Vo và nnk., 2016; Đào Thanh Sơn và nnk., 2016). Do đó, thực hiện nghiên cứu độc học trên $M$. micrura góp phần tạo cơ sở sinh học trong việc sử dụng động vật phù du làm sinh vật cảnh báo sớm nguy cơ ô nhiễm nguồn nước ở Việt Nam dựa vào phân tích các mức độ sống sót và sinh sản của sinh vật để đánh giá độ độc của hóa chất. Bên cạnh đó, phân lập $M$. micrura có ý nghĩa kinh tế khi chúng là một trong những loài được sử dụng làm thức ăn cho cá.

\section{VÂT LIỆU VÀ PHƯƠNG PHÁP NGHIÊN CứU}

\section{Phân lập và nuôi cấy Moina micrura}

Mẫu động vật phù du được thu từ hồ Công viên 29/3 thành phố Đà Nẵng. Moina micrura được định danh theo khóa định loại của Goulden (1968) và Dodsonet al. (2010).

M. micrura được phân lập bằng môi trường nước mềm được đề nghị bởi Hội thử nghiệm và vật liệu Hoa Kỳ (môi trường ASTM). Mẫu phân lập tiến hành trong điều kiện chu kì sáng:tối là $12: 12$ giờ và thức ăn được bổ sung hàng ngày với vi tảo lục Chlorella vulgaris $\left(10^{5}\right.$ tế bào/l) tươi, được cung cấp từ phòng thí nghiệm công nghệ sinh học tảo, Khoa Sinh-Môi trường, trường Đại học Sư phạm, Đại học Đà Nẵng. Trong quá trình thử nghiệm, môi trường nuôi được thay mới 3 lần/tuần. Con non $M$. micrura dưới 24 giờ tuổi được sử dụng cho tất cả các thí nghiệm trong nghiên cứu. Môi trường nước mềm sử dụng trong phân lập được sử dụng làm môi trường nền trong các thí nghiệm độc học cấp tính và độc học mãn tính.

\section{Thí nghiệm thử độc cấp tính}

Mười nồng độ $\mathrm{K}_{2} \mathrm{Cr}_{2} \mathrm{O}_{7} 0,00$ (mẫu đối chứng);0,05;0,08;0,1;0,125;0,2;0,25; 0,$375 ; 0,5$ và $0,8 \mathrm{mg} / 1$ được đưa vào thử nghiệm với 4 lần lặp lại cho mỗi nồng độ, mỗi lần lặp thử nghiệm với 4 cá thể $M$. micrura. Sinh vật được nuôi thử nghiệm trong môi trường có thể tích $20 \mathrm{ml}$, không cho ăn và nuôi hoàn toàn trong tối suốt quá trình thí nghiệm. M. micrura được duy trì trong khoảng thời gian 48 giờ. Các giá trị nhiệt độ và $\mathrm{pH}$ được kiểm tra hằng ngày bằng máy đo $\mathrm{pH}$ (Mettler Toledo). Số lượng cá thể chết được xác định ở 3 mốc thời gian sau 12,24 và 28 giờ để xác định được $\mathrm{LC}_{50}$ theo mốc thời gian.

\section{Thí nghiệm thử độc mãn tính}

Sinh vật được phơi nhiễm ở 5 nồng độ 0,$002 ; 0,005 ; 0,01 ; 0,0125 ; 0,02 ; 0,05$ và 0,00 (mẫu đối chứng). Mỗi nồng độ được lặp lại 4 lần, mỗi lần lặp thử nghiệm với một cá thể $M$. micrura. Thí nghiệm được thực hiện trong môi trường nuôi cấy tĩnh với thể tích $20 \mathrm{ml}$. Môi trường thử nghiệm được làm mới 2 ngày 
một lần chuyển cá thể nuôi sang bình nuôi mới đã được pha sã̃n môi trường thử nghiệm cùng nồng độ phơi nhiễm tương ứng. Sinh vật được cho ăn hàng ngày bằng tảo Chlorella vulgaris với mật độ $10^{5}$ tế bào/l. Thí nghiệm được thực hiện trong 10 ngày (240 giờ). Nhiệt độ và $\mathrm{pH}$ được kiểm tra hăng ngày bằng máy Mettler Toledo. Các tham sô được theo dõi trong quá trình thử nghiệm để xác định giá trị $\mathrm{EC}_{50}$ gồm: 1) Số lượng con mẹ còn sống cuối thí nghiệm; 2) Tổng sổ trứng của một con mẹ; 3) Tổng số con sống cuối thí nghiệm được sinh ra từ một con mẹ. Các thí nghiệm được kiểm tra hằng ngày để xác định số con được sinh ra, tách ra khỏi con mẹ và nuôi riêng trong cốc khác đến khi kết thúc thí nghiệm.

\section{Phương pháp phân tích số liệu}

Số liệu được so sánh các giá trị trung bình bằng phân tích phương sai (ANOVA) và kiểm tra Tukey's với $\alpha=0,05$ và phân tích tương quan hồi quy trên phần mềm $\mathrm{R} \quad(\mathrm{R}$
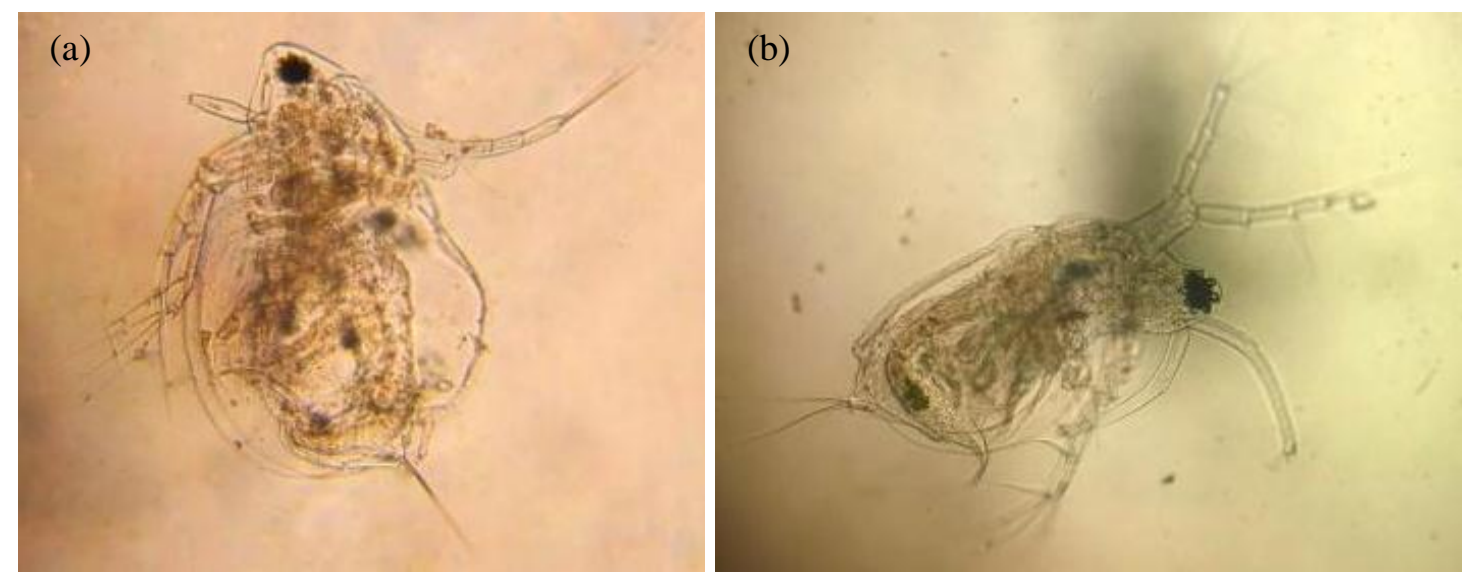

Hình 1. Moina micrura cái (a) và đực (b)
Chiều dài và chiều rộng trung bình tương ứng của $M$. micrura cái là $530 \pm 80 \mu \mathrm{m}$ và $328 \pm 60 \mu \mathrm{m}$, lớn hơn so với $M$. micrura được thu và phân lập tại hồ bê tông thuộc khuôn viên trường đại học Christ (Irinjalakuda, Ân Độ) (kích thước tương ứng là $490 \mu \mathrm{m}$ và $240 \mu \mathrm{m})($ Jana, 1985).

Để đánh giá tính nhạy cảm của $M$. micrura đối với độc chất $\mathrm{K}_{2} \mathrm{Cr}_{2} \mathrm{O}_{7}$, thực hiện nghiên cứu xác định ngưỡng nồng độ độc chất làm chết $50 \%$ cá thể tại 3 mốc thời gian 12,24
Development Core Team, 2013). Dũ liệu từ thử nghiệm độc cấp tính và mãn tính được phân tích bằng phương pháp Probit để tính giá trị $\mathrm{LC}_{50}$ và $\mathrm{EC}_{50}$ (Gaddum, 1948).

\section{KẾT QUẢ VÀ THẢO LUẬN}

Mẫu phù du được thu và phân lập thành công từ hồ Công viên 29/3 được chúng tôi xác định là loài Moina micrura, theo những đặc điểm hình thái sau (hình 1):

Râu II có 2 nhánh, mỗi nhánh có 3 lông. Một nhánh của râu II có 4 đốt, nhánh còn lại có 3 đốt. Râu I chỉ có một đốt, chiều dài gần bằng chiều rộng của đầu. Đầu lớn có hốc mắt rất phát triển và mắt lớn, không có sự xuất hiện của ocellus. Đuôi bụng (postabdomen) ngắn và rộng, có 3 đến 11 răng và 1 răng đôi rât dài.

M. micrura đực có cơ thể nhỏ hơn con cái. Con đực và cái được phân biệt qua râu $\mathrm{I}$, ở con đực bộ phận này dài gấp gần 4 lần ở con cái.

và 48 giờ. Trong, quá trình tiến hành thí nghiệm, các yếu tố nhiệt độ, $\mathrm{pH}$ được kiểm soát nằm trong khoảng đảm bảo cho sự sinh trưởng và phát triển của $M$. micrura. $\mathrm{pH}$ trung bình trong thời gian thí nghiệm dao động khoảng 7,78 $\pm 0,10$, nhiệt độ trong quá trình thí nghiệm được duy trì ở 27,07 $\pm 0,29^{\circ} \mathrm{C}$.

Qua kết quả phân tích cho thấy có sự tương quan thuận giữa nồng độ $\mathrm{K}_{2} \mathrm{Cr}_{2} \mathrm{O}_{7}$ với tỷ lệ phần trăm số lượng cá thể chết. Hệ số tương quan $(\mathrm{r})$ giữa nồng độ và các biến đều 
có sự tương quan rất mạnh $(\mathrm{r}>0,8)$, độ tin cậy cao $\mathrm{p}<0,01$. Điều này cho thấy $M$. micrura có sự nhạy cảm cao đối với độc chất
$\mathrm{K}_{2} \mathrm{Cr}_{2} \mathrm{O}_{7}$, có thể sử dụng để phát hiện ô nhiễm $\mathrm{Cr}^{6+}$, cảnh báo những rủi ro sinh thái đối với môi trường và sinh vật.
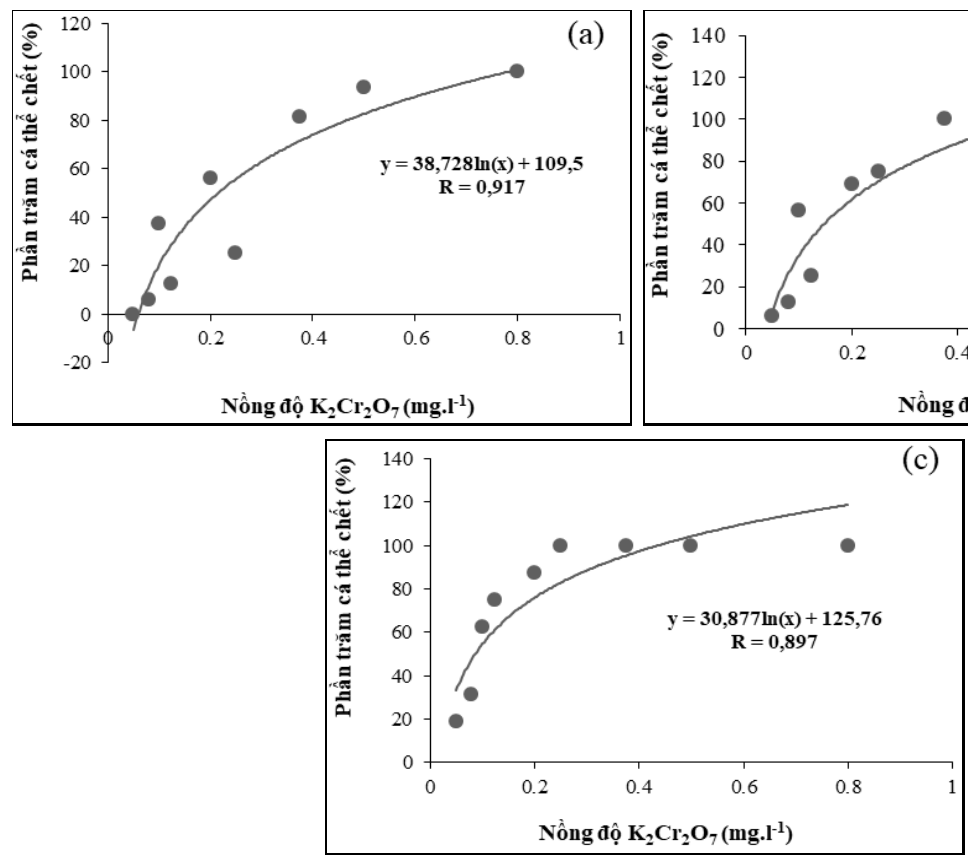

(b)

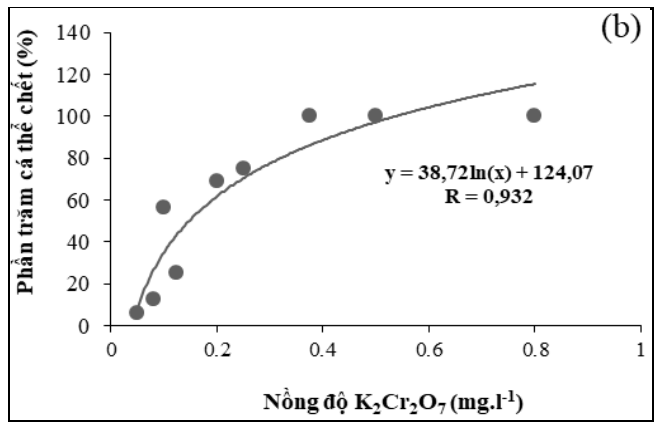

(c)

Hình 2. Tương quan giữa nồng độ $\mathrm{K}_{2} \mathrm{Cr}_{2} \mathrm{O}_{7}$ và phần trăm cá thể chết qua 12 giờ $(\mathrm{a})$, $24 \mathrm{~h}(\mathrm{~b})$ và 48 giờ $(\mathrm{c})$

Giá trị 12-h $\mathrm{LC}_{50}$, 24-h $\mathrm{LC}_{50}$ và $48-\mathrm{h} \mathrm{LC}_{50}$ lần lượt là $0,26 \mathrm{mg} .1^{-1}, 0,15 \mathrm{mg} .1^{-1}$ và 0,08 $\mathrm{mg} \cdot \mathrm{l}^{-1}$. Trong đó, tại nồng độ $0,05 \mathrm{mg} \cdot \mathrm{l}^{-1}$ $\mathrm{K}_{2} \mathrm{Cr}_{2} \mathrm{O}_{7}$ trong thời gian thử nghiệm $12 \mathrm{~h}$ không có biểu hiện chết của sinh vật. Trong suốt thí nghiệm này, mẫu đối chứng có mức sống sót là $100 \%$ (hình 2 ).

So sánh giá trị $48-\mathrm{h} \mathrm{LC}_{50}$ của $\mathrm{K}_{2} \mathrm{Cr}_{2} \mathrm{O}_{7}$ giữa các loài cladoceran, $M$. micrura nhạy cảm tương đồng với loài Pseudosida ramosa (0,08 mg. $\left.\mathrm{l}^{-1}\right)$ (Jaishankar, 2014). Trái lại, $M$. micrura nhạy cảm hơn nhiều lần so với loài Daphnia magna $\left(1,57 \mathrm{mg} . \mathrm{l}^{-1}\right)$ (Lu \& cs., 2017). Tương tự, khi so sánh với loài Ceriodaphnia cornuta được phân lập từ sông Sài Gòn-Đồng Nai (Lan Chi, 2004), M. micrura nhạy cảm hơn $C$. cornuta $(1,8$ lần) đối với độc chất $\mathrm{K}_{2} \mathrm{Cr}_{2} \mathrm{O}_{7}$. Điều này có thể giải thích do môi trường sông Sài Gòn-Đồng Nai chịu ảnh hưởng từ nước thải của ngành nghề sản xuất dệt nhuộm, may mặc, với đặc trưng hàm lượng $\mathrm{Cr6}+$ cao. Vì vậy, loài $C$. cornuta được phân lập từ môi trường này có sức chống chịu với $\mathrm{Cr}^{+6}$ cao hơn.

Đối với các loài động vật bậc cao hơn, nghiên cứu này vẫn chứng tỏ $M$. micrura là một loài nhạy cảm hơn nhiều với độc chất $\mathrm{K}_{2} \mathrm{Cr}_{2} \mathrm{O}_{7}$. Loài cá ngựa vằn (Danio rerio) được phơi nhiễm với $\mathrm{K}_{2} \mathrm{Cr}_{2} \mathrm{O}_{7}$, giá trị 48 -h $\mathrm{LC}_{50}$ của con trưởng thành là $141,38 \mathrm{mg} .1^{-1}$ $\mathrm{Cr}^{+6}$ (Domingues \& nnk., 2010), cao gấp nhiều lần $M$. micrura. Bên cạnh đó, loài vi khuẩn Vibrio fischeri được chứng minh kém nhạy cảm hơn $M$. micrura, với giá trị 24-h $\mathrm{LC}_{50}$ là $799 \pm 126 \mu \mathrm{mol}^{-1} \mathrm{l}^{-1} \mathrm{Cr}^{+6}$ (tương ứng với 117,45 mg.l ${ }^{-1} \mathrm{~K}_{2} \mathrm{Cr}_{2} \mathrm{O}_{7}$ ) (Fulladosa et al., 2005). Qua kết quả độc cấp tính, nghiên cứu cho thấy $M$. micrura là một loài phù hợp cho việc giám sát chromium ở nồng độ thấp trong nước.

Nghiên cứu đánh giá độc chất $\mathrm{K}_{2} \mathrm{Cr}_{2} \mathrm{O}_{7}$ qua hai tham số là số lượng trứng và con sinh ra còn sống đến cuối thí nghiệm bởi một con 
mẹ. Giá trị $\mathrm{pH}$ và nhiệt độ được quy trì ổn định trong suốt thí nghiệm, với $\mathrm{pH}$ dao động trong khoảng $7,74 \pm 0,11$ và nhiệt độ trong khoảng $25,08 \pm 0,25^{\circ} \mathrm{C}$.
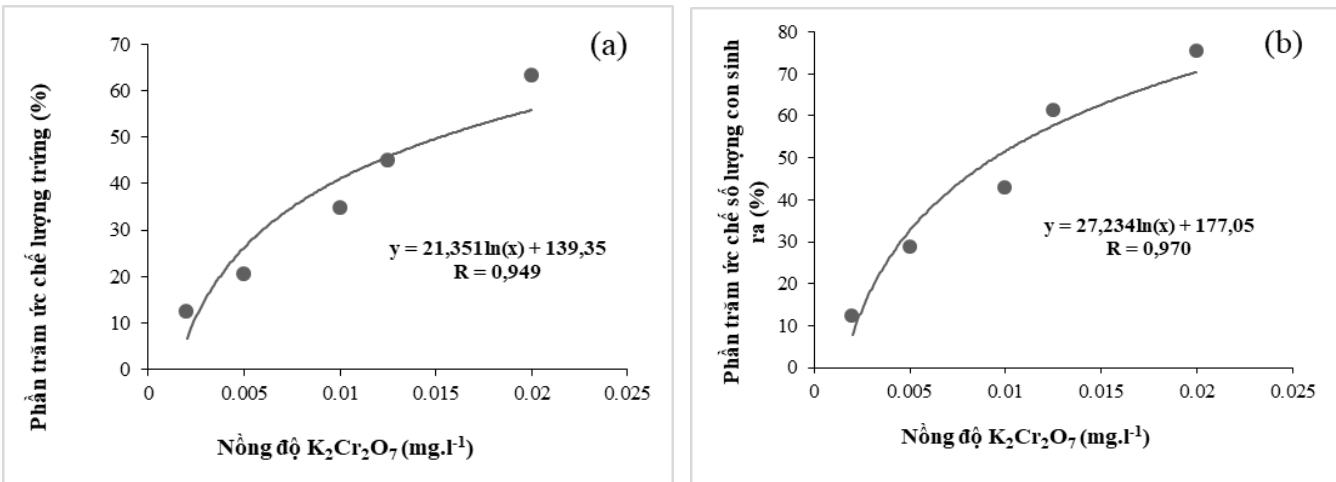

Hình 3. Tương quan giữa nồng độ $\mathrm{K}_{2} \mathrm{Cr}_{2} \mathrm{O}_{7}$ và phần trăm ức chế lượng trứng (a), sô lượng con sinh ra (b)

Mối tương quan giữa lượng trứng, tổng số con non sinh ra với độc chất potassium dichromate được thể hiện ở hình 3 cho thấy, giữa chúng có mối tương quan thuận. Hệ số tương quan (r) giữa nồng độ và các tham số đều có sự tương quan rất mạnh $(\mathrm{r}>0,9)$, điều này cho thấy có sự tương quan tốt và độ tin cậy cao giữa nồng độ độc chất với các biến.

Kết quả nghiên cứu cho thấy giá trị $\mathrm{EC}_{50}$ trong 10 ngày thử nghiệm của $M$. micrura là $0,015 \mathrm{mg} .1^{-1}$ đối với biến số lượng trứng và $\mathrm{EC}_{50}=0,009 \mathrm{mg} . \mathrm{l}^{-1}$ đối với biến con sống đến cuối thí nghiệm. Điều này cho thấy, $M$. micrura là một loài nhạy cảm hơn so với $D$. magna và $D$. pulex, là những loài thường được sử dụng trong thử nghiệm độc học mãn tính. Kühn et al. (năm ?) đã thực hiện đánh giá ảnh hưởng của độc chất lên $D$. magna, nồng độ không quan sát thấy phản ứng $\mathrm{NOEC}=0,018$ $\mathrm{mg} .1^{-1}$ (Jaishankar, 2014), trong khi đó nồng độ gây ức chế $50 \%$ số lượng trứng và con sinh ra bởi một con mẹ lần lượt là $0,015 \mathrm{mg} \cdot \mathrm{l}^{-1}$ và $0,009 \mathrm{mg} \cdot \mathrm{l}^{-1}$. So sánh này cho thấy $M$. micrura nhạy cảm hơn $D$. magna đối với ảnh hưởng mãn tính của độc chất $\mathrm{K}_{2} \mathrm{Cr}_{2} \mathrm{O}_{7}$. Kết quả khẳng định thêm cho tiềm năng sử dụng loài M. micrura như một sinh vật giám sát chất lượng nước trong thời gian dài (240 giờ).

\section{KẾT LUẬN}

Nghiên cứu đã phân lập được loài Moina micrura từ hồ Công viên $29 / 3$ Đà Nẵng. $M$. micrura sinh trưởng và phát triển tốt trong môi trường nước mềm ASTM. $M$. micrura rât nhạy cảm với độc chất $\mathrm{K}_{2} \mathrm{Cr}_{2} \mathrm{O}_{7}$, biểu hiện bằng những thay đổi bất thường trong khả năng sống sót và sinh sản của chúng. Do đó, chúng có thể ứng dụng làm sinh vật chỉ thị chất lượng môi trường nước.

Nghiên cứu này chỉ bước đầu đánh giá sự nhạy cảm của $M$. micrura với độc chất $\mathrm{K}_{2} \mathrm{Cr}_{2} \mathrm{O}_{7}$, cần nghiên cứu đa dạng loại độc chất hơn trên $M$. micrura nói riêng và sinh vật nói chung nhằm tạo $\mathrm{ra}$ cơ sở dữ liệu cho việc đánh giá độc học trên sinh vật.

\section{TÀI LIÊU THAM KHẢO}

Bodar C. W. M., Zee A. V. D., Voogt P. A., Wynne, H., Zandee D. I., 1989. Toxicity of heavy metals to early life stages of Daphnia magna. Ecotoxicology and Environmental Safety, 17(3): 333-338.

Dodson S. L., Cáceres C. E., Rogers, D. C., 2010. Cladocera and other Branchiopoda. In Ecology and classification of North American freshwater invertebrates. Academic Press, pp. 773-827

Domingues I., Oliveira R., Lourenço J., Grisolia C. K., Mendo S., Soares A. M. V. M., 2010. Biomarkers as a tool to assess effects of chromium (VI): comparison of responses in zebrafish early life stages and adults. Comparative Biochemistry and 
Physiology Part C. Toxicology \& Pharmacology, 152(3): 338-345.

Đào Thanh Sơn, Trần Phước Thảo, Nguyễn Thị Thu Liên, Nguyễn Thanh Sơn, Bùi Bá Trung, 2016. Ghi nhận đầu tiên về độc tính của loài vi khuẩn lam Planktohrix rubescens phân lập từ ao nuôi cá tỉnh Sóc Trăng. Tap chi Sinh hoc, 38(1): 115-123.

Fulladosa E., Murat J. C., Villaescusa I., 2005. Effect of cadmium (II), chromium (VI), and arsenic (V) on long-term viability-and growth-inhibition assays using Vibrio fischeri marine bacteria. Archives of Environmental Contamination and Toxicology, 49(3): 299-306.

Gaddum J. H., 1948. Probit Analysis. Nature., 161(4090): 417-418.

Goulden C. E., 1968. The systematics and evolution of the Moinidae. Transactions of the American Philosophical Society, 58(6): 1-101.

Iwai C. B., Somparn A., Noller B., 2011. Using zooplankton, Moina micrura Kurz to evaluate the ecotoxicology of pesticides used in paddy fields of Thailand. In Pesticides in the Modern World-Risks and Benefits. InTech, pp: 267-280.

Jacobs J. A., Testa S. M., 2005. Overview of chromium (VI) in the environment: background and history. Chromium (VI) handbook, 1-21.

Jaishankar M., Tseten T., Anbalagan N., Mathew B. B., Beeregowda K. N., 2014. Toxicity, mechanism and health effects of some heavy metals. Interdisciplinary Toxicology, 7(2): 60-72.

Jana B. B., Pal G. P.,1985. The life history parameters of Moina micrura (Kurz.) grown in different culturing media. Water Research, 19(7): 863-867.
Kühn R., Pattard M., Pernak K. D., Winter, A., 1989. Results of the harmful effects of water pollutants to Daphnia magna in the 21-day reproduction test. Water Research, 23(4): 501-510.

Lan Chi D. H., BeckerVan Slooten K., Tarradellas J., 2004. Tropical ecotoxicity testing with Ceriodaphnia cornuta. Environmental Toxicology: An International Journal, 19(5): 497-504.

Lu G., Yang H., Xia J., Zong Y., Liu J., 2017. Toxicity of $\mathrm{Cu}$ and $\mathrm{Cr}$ nanoparticles to Daphnia magna. Water, Air \& Soil Pollution, 228(1): 18.

Lê Huy Tuấn, Bùi Thị Dịu, Lê Thị Ánh Tuyết, 2016. Nghiên cứu độc tính cấp của florfenicol đối với một số loài sinh vật thủy sinh. Tap chi Khoa hoc, Truờng Đại hoc Hồng Đức, 30: 145-155.

Nguyễn Trung Kiên, Trần Thị Thu Hương, Dương Thị Thủy, 2017. Ảnh hưởng độc tính của vật liệu nano đồng $(\mathrm{Cu})$ đển sự sinh trưởng của Daphnia magna Strauss. Tap chí Sinh hoc, 39(2): 245-251.

Petrusek A., Černý M., Audenaert E., 2004. Large intercontinental differentiation of Moina micrura (Crustacea: Anomopoda): one less cosmopolitan ladoceran? Hydrobiologia, 526(1): 73-81.

R Development Core Team, 2013. R: A Language and Environment for Statistical Computing. R Foundation for Statistical Computing, Vienna, Austria.

Vo T. M. C., Pham T. L., Dao T. S., 2016. Detrimental impacts of toxic Microcystis aeruginosa from Vietnam on life history traits of Daphnia magna. Journal of Vietnamese Environment, 8(1): 56-61.

Warren E., 1900. Memoirs: On the Reaction of Daphnia magna (Straus) to certain Changes in its Environment. Journal of Cell Science, 2(170): 199-224. 